\title{
COMPORTAMENTO DE DIFERENTES FONTES DE SILÍCIO NO SOLO E NA CULTURA DO TOMATEIRO(1)
}

\author{
H. S. PEREIRA(2), G. C. VITTI (3) \& G. H. KORNDORFER ${ }^{(2)}$
}

\begin{abstract}
RESUMO
O objetivo deste trabalho foi estudar a ação do xisto, de duas escórias e de um termofosfato sobre a disponi bilidade do Si no Argissolo Vermelho-Amarelo sob plasticultura com o tomateiro. Dois experimentos foram instalados em blocos casualizados com os seguintes tratamentos: testemunha, $6 \mathrm{t} \mathrm{ha}^{-1}$ de xisto, $6 \mathrm{t} \mathrm{ha} \mathrm{a}^{-1}$ de escória da Mannesman, $6 \mathrm{t}$ ha $^{-1}$ de escória da Dedini e 2,5 t ha-1 de termofosfato. As concentrações de $\mathrm{Si}\left(\mathrm{SiO}_{2}\right.$ total) nestes produtos foram: 530, 350, 273, $185 \mathrm{~g} \mathrm{~kg}^{-1}$, respectivamente, para o xisto, escória da Mannesman, Dedini e termofosfato. Os resultados indicaram que a escória da Mannesman foi o tratamento que apresentou maiores teores de Si no solo, extraídos com oxalato de amônio, e o xisto o tratamento com o menor teor. Todavia, avaliando a relação entre a quantidade de Si aplicada sobre o aumento de Si no solo, verifica-se que o termofosfato foi o tratamento que mais elevou o teor deste elemento. Os produtos aplicados forneceram Si para o tomateiro, mas não foram suficientes para aumentar a produtividade. Observou-se boa correlação entre os teores de Si na planta em relação ao Si extraído do solo com oxalato de amônio.
\end{abstract}

Termos de indexação: xisto, escórias, termofosfato, tomate.

(1) Parte da Tese de Doutorado do primeiro autor, defendida junto à Escola Superior de Agricultura “Luiz de Queiroz" - ESALQ/US. Apoio FAPESP. Recebido para publicação em outubro de 2001 e aprovado em outubro de 2002.

(2) Pesquisador do Instituto de Ciências Agrárias, Universidade Federal de Uberlândia - UFU. Caixa Postal 593, CEP $38400-902$ Uberlândia (MG). Bolsista CNPq. E-mail: hsp@iciag.ufu.br; ghk@triang.com.br

(3) Professor Titular da Escola Superior de Agricultura “Luiz de Queiroz" - ESALQ/USP. Caixa Postal 9 CEP 13418-970, Piracicaba (SP). E-mail: gcvitti@carpa.ciagri.usp.br 


\title{
SUMMARY: BEHAVIOR OF DIFFERENT SILICON SOURCES IN THE SOIL AND IN TOMATO CROP
}

\begin{abstract}
The objective of this study was to evaluate the reactivity of four Si sources: schist, two types of slag and a thermal-phosphatebased on Si availability in theTypic Eutrustults and in thetomato crop uptake Two experiments werecarried out in a randomized bl ock design with the following treatments: check plot, $6 \mathrm{t} \mathrm{ha}^{-1}$ of schist, $6 \mathrm{t} \mathrm{ha}^{-1}$ of Mannesman slag, $6 \mathrm{t} \mathrm{ha}^{-1}$ of Dedini slag and $2.5 \mathrm{t} \mathrm{ha}^{-1}$ of thermal-phosphate. The Si content $\left(\mathrm{SiO}_{2}\right.$ total $)$ in the products was: schist $530 \mathrm{~g} \mathrm{~kg}^{-1}$, Mannesman slag $350 \mathrm{~g} \mathrm{~kg}^{-1}$, Dedini slag $273 \mathrm{~g} \mathrm{~kg}^{-1}$ and thermal-phosphate $185 \mathrm{~g} \mathrm{~kg}^{-1}$. Silicon levels in the soil, extracted by ammonium oxalate, were highest in the Mannesman slag treatment, while the schist treatment presented the lowest levels. The relationship among Si application and Si in the soil, however, showed that thermal-phosphate was more efficient compared to the others Si sources. The applied $\mathrm{Si}$ sources wereable to provideSi for thetomato, but wereinsufficient to increaseyiedds. A good correlation was observed between theSi plant content and Si extracted with ammonium oxal ate from the soil.
\end{abstract}

Index terms: schist, slag, thermal-phosphate, tomato.

\section{INTRODUÇÃO}

A sílica solúvel em solos não tem sido estudada intensivamente, principalmente por não ser o Si considerado essencial às plantas. Contudo, mesmo não sendo essencial, do ponto de vista fisiológico, ao crescimento e desenvolvimento das plantas, oSi, em numerosos casos, demonstrou efeito benéfico sobre o aumento de produção de diversas culturas, como, por exemplo, a cana-de-açúcar, o arroz e outras gramíneas (Epstein, 1994). Acredita-se que oSi possa diminuir a incidência de doenças e até mesmo o ataque de insetos, graças ao seu acúmulo abaixo da cutícula, a qual oferece resistência mecânica contra esses organismos. Além disso, o Si pode interferir na arquitetura das plantas, favorecendo a fotossíntese, ao proporcionar folhas mais eretas, o que significa maior eficiência fotossintética.

Os sol os tropicais são, de modo geral, altamente intemperizados, onde os minerais primários facilmente intemperizáveis que contêm Si são quase inexistentes. Esses solos apresentam, em alguns casos, teores menores do que $2 \mathrm{mg} \mathrm{kg}^{-1}$ no extrato saturado (Fox \& Silva, 1978).

As escórias básicas de siderurgia podem ser utilizadas como corretivos de sol o e como fonte de $\mathrm{Si}$ eoutros nutrientes. São constituídas principalmente de silicatos de $\mathrm{Ca}$ e $\mathrm{Mg}$, podendo conter impurezas, tais como: P, S, Fe, Zn, Cu, B, Mo, Co e outros. Os silicatos comportam-se de maneira similar aos carbonatos no solo e são capazes de elevar o pH, neutralizando o Al trocável e outros elementos tóxicos (Alcarde, 1992).

Durante o processo para a obtenção do ferro-gusa, a sílica do minério de ferro reage com o cálcio do cal cário no al to forno, produzindo um silicato decálcio com impurezas. O material fundidoéresfriado, seco e moído. Para cada 4 t de ferro-gusa produzidas, é gerada, em média, 1 t de escória de alto forno (Coelho, 1998). O Brasil é o sexto maior produtor mundial de ferro-gusa, com uma produção anual de cerca de 25 milhões de toneladas, o que corresponde à geração de cerca de 6,25 milhões de toneladas de escória por ano. O estado de Minas Gerais éo maior produtor nacional, responsável por mais da metade de todo ferro-gusa produzido no Brasil.

O termofosfato obtido pela fusão de rocha fosfatada com serpentinito (silicato de magnésio) a $1.500{ }^{\circ} \mathrm{C}$ também apresenta considerável quantidade de $\mathrm{Si}$ em sua composição $\left(\mathrm{SiO}_{2}=25 \mathrm{dag} \mathrm{kg}^{-1}\right)$. A adição de termofosfato ao solo como fonte de Si mostra-se satisfatória para a cultura do arroz, segundo Freire et al. (1985).

O xisto betuminoso é uma rocha essencial mente silto-argil osa denominada "fol hel hos ol eígenos", com conteúdo apreciável de matéria orgânica (14$28 \mathrm{dag} \mathrm{kg}^{-1}$ ) e que, sob aquecimento, pode produzir óleo, gás e S. A fração clástica é formada principalmente por quartzo de grãos muito finos e quantidades variáveis de sericita, moscovita, dorita, argilo-mineral (ilita dominante) e plagioclásio, fazendo com quetenha mais de $50 \%$ deSi. O Brasil dispõe da segunda maior reserva de folhelhos ol eígenos (xisto) do mundo, constituindo os depósitos da formação Irati a maior reserva brasileira de combustíveis e produtos sulfurosos (Prien, 1975; Bigarella, 1975). O principal problema, que limita o desenvolvimento da indústria do xisto, é a disposição do xisto retortado (xisto após a retirada do óleo e S) no ambiente, para não afetá-lo ecologicamente (Gratt, 1985; Stark \& Redente, 1986). A alta alcalinidade deste resíduo, valores de $\mathrm{pH}$ ao redor de 12, é um dos fatores que impedem, de 
maneira severa, a revegetação direta (Reddy \& Lindsay, 1986).

O Si apresenta-se em determinados compostos (silicatos/escórias) fortemente ligado ao mineral e, portanto, pouco aproveitável pelas plantas. Assim sendo, os teores totais de Si nem sempre indicam seu potencial de uso como fertilizante silicatado. Portanto, é preciso identificar e avaliar o potencial agronômico dessas fontes por meio de métodos químicos e biológicos.

\section{MATERIAL E MÉTODOS}

Este trabalho foi realizado em duas áreas correspondentes a dois experimentos com as seguintes características: Experimento 1 - instalado em 1997 no município de Piracicaba (SP) sobre um Argissolo Vermel ho-Amarel o eutrófico abrúptico "A" moderado textura arenosa/média, cujas características químicas na camada de $0-20 \mathrm{~cm}$ são: $\mathrm{pH}\left(\mathrm{CaCl}_{2}\right)$ 5,2; M.O. $\left(\mathrm{g} \mathrm{kg}^{-1}\right)$ 15; P $\left(\mathrm{mg} \mathrm{dm}^{-3}\right) 111 ; \mathrm{K}$ $\left(\mathrm{mmol}_{\mathrm{C}} \mathrm{dm}^{-3}\right)$ 1,7; $\mathrm{Ca}\left(\mathrm{mmol}_{\mathrm{C}} \mathrm{dm}^{-3}\right)$ 29; $\mathrm{Mg}\left(\mathrm{mmol}_{\mathrm{C}} \mathrm{dm}^{-3}\right)$ 14; e H + Al $\left(\mathrm{mmol}_{\mathrm{c}} \mathrm{dm}^{-3}\right)$ 20; e Experimento 2 instalado em 1998 no município de Tabapuã (SP) também sobre um Argissolo Vermel ho-Amarelo eutrófico "A" moderado textura arenosa/média, cujas características químicas são as seguintes: $\mathrm{pH}\left(\mathrm{CaCl}_{2}\right)$ 5,0; M.O. $\left(\mathrm{g} \mathrm{kg}^{-1}\right)$ 17; P $\left(\mathrm{mg} \mathrm{dm}^{-3}\right)$ 90; K $\left(\mathrm{mmol}_{\mathrm{C}} \mathrm{dm}^{-3}\right)$ 2,8; $\mathrm{Ca}\left(\mathrm{mmol}_{\mathrm{C}} \mathrm{dm}^{-3}\right) 28 ; \mathrm{Mg}\left(\mathrm{mmol}_{\mathrm{c}} \mathrm{dm}^{-3}\right)$ 9; $\mathrm{eH}+\mathrm{Al}$ $\left(\mathrm{mmol}_{\mathrm{c}} \mathrm{dm}^{-3}\right) 34$.

Os tratamentos constaram de: testemunha, $6 \mathrm{t} \mathrm{ha}^{-1}$ de xisto, $6 \mathrm{t} \mathrm{ha}^{-1}$ de escória da Mannesman, $6 \mathrm{t} \mathrm{ha}^{-1}$ de escória da Dedini e 2,5 $\mathrm{Mg} \mathrm{ha}^{-1}$ de termofosfato. As concentrações de $\mathrm{Si}\left(\mathrm{SiO}_{2}\right.$ total $)$ nos produtos foram: xisto $=530 \mathrm{~g} \mathrm{~kg}^{-1}$, escória da Mannesman $=350 \mathrm{~g} \mathrm{~kg}^{-1}$, escória da Dedini $=$ $273 \mathrm{~g} \mathrm{~kg}^{-1}$ e termofosfato $=185 \mathrm{~g} \mathrm{~kg}^{-1}$. $\quad \mathrm{O}$ delineamento experimental utilizado foi o de blocos casualizados com quatro repetições. Os experimentos foram instalados em casa devegetação (plasticultura), de estrutura metálica na forma de arco com $7 \mathrm{~m}$ de largura por $60 \mathrm{~m}$ de comprimento, altura do vão central com 4,5 m, e cobertura com plástico transparente de $150 \mu \mathrm{m}$ e com as laterais fechadas com tela de sombrite preto a $30 \%$.

A obtenção das mudas de tomate foi feita pelo plantio em bandeja de isopor com 128 células, usando-se como substrato o plantmax da Eucatex. Vinte e cinco dias após a germinação das sementes, foi realizado o transplante das mudas, colocando-as em linhas duplas com espaçamento de $0,5 \times 0,5 \times 1,25(0,5$ m entre plantas, 0,5 m na linha dupla e 1,25 m entre as linhas duplas de plantio). As parcelas constaram de uma linha dupla de $6 \mathrm{~m}$ de comprimento, perfazendo uma área de 10,5 m² por parcela. A adubação básica de plantio e os tratamentos foram aplicados a lanço na área total da parcela, antes do plantio, e incorporados com enxada rotativa a uma profundidade de $12 \mathrm{~cm}$, no experimento 1 , e de $17 \mathrm{~cm}$, no experimento 2 . Nesta adubação, foram aplicados $450 \mathrm{~kg} \mathrm{ha}^{-1}$ de $\mathrm{P}_{2} \mathrm{O}_{5}$ na forma de superfosfato triplo, exceto no tratamento com termofosfato, em que o $\mathrm{P}_{2} \mathrm{O}_{5}$ foi fornecido pelo mesmo. A adubaçãoNK foi aplicada via fertirrigação no sistema de gotejamento, seguindo as recomendações deTrani \& Raij (1996) para a cultura do tomate.

Além das adubações NPK, foram feitas, semanalmente, após o início da frutificação, adubações via foliar com $\mathrm{Ca}\left(\mathrm{CaCl}_{2}\right.$ a 0,15 dag $\left.\mathrm{L}^{-1}\right)$, $\mathrm{Mg}$ (Profol Mg a 0,05 dag $\mathrm{L}^{-1}$ ), B (Ácido bórico a 0,07 dag $^{-1}$ ) e $M n$ (Profol $M n$ a 0,05 dag $L^{-1}$ ). No experimento 1, as aplicações de Mg e Mn iniciaramse com a colheita, quando foram verificados, em algumas plantas, sintomas de deficiência destes elementos, portanto após a coleta das amostras de folhas. J á no experimento 2, estas aplicações ocorreram desde o início das pulverizações.

No período do aparecimento do primeiro fruto maduro, foram real izadas as amostragens defol has, coletando-sea fol ha logo abaixo e oposta ao segundo cacho floral (Malavolta et al., 1997). Para a determinação dos el ementos, foram separados folíol os e pecíol os em amostras distintas, e os teores dos macronutriente ( $\mathrm{N}, \mathrm{P}, \mathrm{K}, \mathrm{Ca}, \mathrm{Mg}$ e $\mathrm{S})$ e de micronutrientes ( $B, C u, F e, M n$ e $\mathrm{Zn}$ ) foram determinados conforme métodos apresentados por Malavolta et al. (1997). O Si foi determinado pelo método descrito por Korndörfer et al. (1999), que consiste basicamente na extração do Si no material vegetal por digestão com água oxigenada ehidróxido de sódio em autoclave. A determinação foi feita pela formação do complexo BETA-molibdosilicato amarel o e leitura em espectrofotômetro a $410 \mathrm{~nm}$.

As colheitas foram realizadas duas vezes por semana, num período de pouco mais de dois meses, até atingir a nona penca. Logo após o final das colheitas, procedeu-se à amostragem de solo nas profundidades de 0-10 e 10-20 cm, retirando-se as amostras entre as linhas duplas de plantio com o amostrador de solo do tipo "sonda". As amostras de solo foram analisadas quimicamente, conforme método de Raij \& Quaggio (1983), para as seguintes determinações: $\mathrm{pH}\left(\mathrm{CaCl}_{2}\right), \mathrm{P}, \mathrm{K}, \mathrm{Ca}, \mathrm{Mg}, \mathrm{H}+\mathrm{Al}$; S$\mathrm{SO}_{4}$, conforme Vitti (1989); e os micronutrientes: B, pel o método da áqua quente (Berger \& Truog, 1939), e $\mathrm{Cu}, \mathrm{Fe}, \mathrm{Mn}$ e $\mathrm{Zn}$, pelo método DTPA (Lindsay \& Morvell, 1978). Calcularam-sea soma debases (SB), a capacidade de troca catiônica (CTC) e os valores da saturação por bases $(\mathrm{V})$. A análise do Si no solo foi efetuada extraindo-se o el emento com oxal ato de amônio 0,2 mol L-1 a pH 3,0, conformeSmith (1984). A determinação foi feita pela formação do complexo BETA-mol ibdosilicato reduzi do pel oácido ascórbico ou "azul-de-molibdênio", procedendo-se à leitura no colorímetro a 810 nm (Kilmer, 1965). 


\section{RESULTADO E DISCUSSÃO}

\section{E feito dos tratamentos no solo}

Na análise do solo do experimento 2 (Quadro 1), constataram-se aumentos significativos do pH com a aplicação do termofosfato, nas duas profundidades, e com a escória da Mannesmam, na profundidade de $10-20 \mathrm{~cm}$. No experimento 1, essas variações não foram observadas.

A escória da Mannesmam apresentou aumentos significativos do $\mathrm{Ca}^{2+}$ na camada de $0-10 \mathrm{~cm}$ nos dois experimentos, enquanto com a escória da Dedini, esses aumentos ocorreram significativamente nas duas profundidades. O xisto eo termofosfato, embora apresentem Ca na sua composição, não diferiram da testemunha. Os tratamentos também proporcionaram aumentos nos teores de $\mathrm{Mg}^{2+}$ no solo, mas aumentos significativos só foram observados com o tratamento da Mannesmam (0-10 cm) e Dedini (10$20 \mathrm{~cm}$ ), no experimento 1, e com o termofosfato, no experimento 2 (duas profundidades). Os aumentos nos teores de $\mathrm{Ca}^{2+} \mathrm{e} \mathrm{M} \mathrm{g}^{2+}$ refletiram-se na soma de bases, principal mente nos tratamentos com escórias e termofosfato, demonstrando o efeito corretivo destes produtos, pois estes são formados basi camente por $\mathrm{CaSiO}_{3}$ (Coelho, 1998) e com propriedades corretivas semel hantes às do cal cário (Al carde, 1992).

\section{Quadro 1. Resultados das análises químicas de solo dos experimentos 1 e 2 ao final da colheita}

\begin{tabular}{|c|c|c|c|c|c|c|c|c|c|}
\hline Tratamento (1) & $\mathbf{p H}$ & $\mathrm{S}-\mathrm{SO}_{4}^{2-}$ & $\mathbf{K}^{+}$ & $\mathrm{Ca}^{2+}$ & $\mathbf{M g}^{2+}$ & $\mathbf{H}+\mathbf{A}$ & SB & $\mathbf{T}$ & $\mathbf{v}$ \\
\hline & $\mathrm{CaCl}_{2}$ & $m g \mathrm{dm}^{-3}$ & & 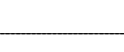 & $\mathrm{mm}$ & $\mathrm{dm}^{-3}$ & 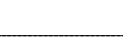 & - & $\%$ \\
\hline & & & & Expe & ento 1: & $10 \mathrm{~cm}$ & & & \\
\hline $\begin{array}{l}\text { Testemunha } \\
\text { Xisto } \\
\text { Escória Mannesman } \\
\text { Escória Dedini } \\
\text { Termofosfato }\end{array}$ & $\begin{array}{l}6,3 \\
6,2 \\
6,6 \\
6,5 \\
6,5\end{array}$ & $\begin{array}{l}23 \mathrm{~b} \\
44 \mathrm{a} \\
33 \mathrm{ab} \\
32 \mathrm{ab} \\
21 \mathrm{~b}\end{array}$ & $\begin{array}{l}1,6 \mathrm{ab} \\
1,6 \mathrm{~b} \\
2,1 \mathrm{a} \\
1,4 \mathrm{~b} \\
1,6 \mathrm{~b}\end{array}$ & $\begin{array}{r}65 \mathrm{~b} \\
68 \mathrm{~b} \\
98 \mathrm{a} \\
101 \mathrm{a} \\
77 \mathrm{ab}\end{array}$ & $\begin{array}{l}16 \mathrm{~b} \\
16 \mathrm{~b} \\
31 \mathrm{a} \\
23 \mathrm{ab} \\
25 \mathrm{ab}\end{array}$ & $\begin{array}{l}14 \\
14 \\
12 \\
12 \\
12\end{array}$ & $\begin{array}{l}82 \mathrm{~b} \\
85 \mathrm{~b} \\
131 \mathrm{a} \\
125 \mathrm{a} \\
103 \mathrm{ab}\end{array}$ & $\begin{array}{l}97 \mathrm{c} \\
100 \mathrm{bc} \\
142 \mathrm{a} \\
137 \mathrm{ab} \\
115 \mathrm{abc}\end{array}$ & $\begin{array}{l}85 \mathrm{~b} \\
85 \mathrm{~b} \\
92 \mathrm{a} \\
91 \mathrm{a} \\
89 \mathrm{ab}\end{array}$ \\
\hline C.V. (\%) & 2,8 & 22,2 & 9,5 & 11,5 & 20,7 & 8,1 & 12,6 & 11,4 & 1,9 \\
\hline \multirow[t]{2}{*}{$\begin{array}{l}\text { Valor F } \\
\text { D.M.S. a } 5 \%\end{array}$} & $\begin{array}{l}1,8 \\
0,5\end{array}$ & $\begin{array}{r}4,1 \\
20,3\end{array}$ & $\begin{array}{l}5,9 \\
0,47\end{array}$ & $\begin{array}{r}7,5 \\
27,9\end{array}$ & $\begin{array}{r}4,2 \\
13,6\end{array}$ & $\begin{array}{l}3,3 \\
3,1\end{array}$ & $\begin{array}{r}6,4 \\
39,6\end{array}$ & $\begin{array}{r}5,6 \\
40,1\end{array}$ & $\begin{array}{l}8,1 \\
5,1\end{array}$ \\
\hline & \multicolumn{9}{|c|}{ Experimento 1: $10-20 \mathrm{~cm}$} \\
\hline $\begin{array}{l}\text { Testemunha } \\
\text { Xisto } \\
\text { Escória Mannesman } \\
\text { Escória Dedini } \\
\text { Termofosfato }\end{array}$ & $\begin{array}{l}5,5 \\
5,4 \\
5,6 \\
5,5 \\
5,2\end{array}$ & $\begin{array}{l}19 \mathrm{~b} \\
54 \mathrm{a} \\
25 \mathrm{~b} \\
20 \mathrm{~b} \\
16 \mathrm{~b}\end{array}$ & $\begin{array}{l}2,7 \\
2,4 \\
2,6 \\
2,1 \\
2,0\end{array}$ & $\begin{array}{l}26 \mathrm{~b} \\
31 \mathrm{~b} \\
36 \mathrm{ab} \\
49 a \\
32 \mathrm{ab}\end{array}$ & $\begin{array}{l}12 \mathrm{~b} \\
12 \mathrm{~b} \\
14 \mathrm{ab} \\
18 \mathrm{a} \\
13 \mathrm{~b}\end{array}$ & $\begin{array}{l}18 \\
21 \\
20 \\
17 \\
20\end{array}$ & $\begin{array}{l}41 \mathrm{~b} \\
45 \mathrm{~b} \\
52 \mathrm{ab} \\
69 \mathrm{a} \\
47 \mathrm{~b}\end{array}$ & $\begin{array}{l}58 b \\
66 a b \\
72 a b \\
86 a \\
67 a b\end{array}$ & $\begin{array}{l}69 \\
68 \\
72 \\
80 \\
70\end{array}$ \\
\hline C.V. (\%) & 5,4 & 22,8 & 16,3 & 17,5 & 11,5 & 13,1 & 14,3 & 10,2 & 5,7 \\
\hline \multirow[t]{2}{*}{$\begin{array}{l}\text { Valor F } \\
\text { D.M.S. a } 5 \%\end{array}$} & $\begin{array}{l}0,6 \\
0,9\end{array}$ & $\begin{array}{l}14,6 \\
18,4\end{array}$ & $\begin{array}{l}1,5 \\
1,4\end{array}$ & $\begin{array}{r}4,7 \\
18,2\end{array}$ & $\begin{array}{l}5,8 \\
4,6\end{array}$ & $\begin{array}{l}0,9 \\
7,4\end{array}$ & $\begin{array}{r}5,2 \\
21,7\end{array}$ & $\begin{array}{r}4,9 \\
21,2\end{array}$ & $\begin{array}{r}3,0 \\
12,3\end{array}$ \\
\hline & \multicolumn{9}{|c|}{ Experimento 2: 0-10 cm } \\
\hline $\begin{array}{l}\text { Testemunha } \\
\text { Xisto } \\
\text { Escória Mannesman } \\
\text { Escória Dedini } \\
\text { Termofosfato }\end{array}$ & $\begin{array}{l}5,7 \mathrm{~b} \\
5,7 \mathrm{~b} \\
6,1 \mathrm{ab} \\
6,3 \mathrm{ab} \\
6,3 \mathrm{a}\end{array}$ & $\begin{array}{r}6 \mathrm{~b} \\
38 \mathrm{a} \\
12 \mathrm{~b} \\
17 \mathrm{~b} \\
9 \mathrm{~b}\end{array}$ & $\begin{array}{l}1,4 \\
1,8 \\
1,9 \\
1,7 \\
2,4\end{array}$ & $\begin{array}{l}60 \mathrm{c} \\
74 \mathrm{bc} \\
94 \mathrm{ab} \\
112 \mathrm{a} \\
85 \mathrm{bc}\end{array}$ & $\begin{array}{l}18 b \\
22 b \\
25 a b \\
26 a b \\
32 a\end{array}$ & $\begin{array}{l}21 a b \\
23 a \\
16 a b c \\
15 b c \\
13 c\end{array}$ & $\begin{array}{l}79 \mathrm{c} \\
98 \mathrm{bc} \\
120 \mathrm{ab} \\
140 \mathrm{a} \\
119 \mathrm{ab}\end{array}$ & $\begin{array}{l}100 \mathrm{~b} \\
121 \mathrm{ab} \\
137 \mathrm{a} \\
155 \mathrm{a} \\
132 \mathrm{ab}\end{array}$ & $\begin{array}{l}78 \mathrm{c} \\
81 \mathrm{bc} \\
88 \mathrm{ab} \\
90 \mathrm{a} \\
90 \mathrm{a}\end{array}$ \\
\hline C.V. (\%) & 3,6 & 24,1 & 19,3 & 10,7 & 12,5 & 13,3 & 10,8 & 9,0 & 3,2 \\
\hline \multirow[t]{2}{*}{$\begin{array}{l}\text { Valor F } \\
\text { D.M.S. a } 5 \%\end{array}$} & $\begin{array}{l}4,9 \\
0,6\end{array}$ & $\begin{array}{l}23,4 \\
11,9\end{array}$ & $\begin{array}{l}2,5 \\
1,1\end{array}$ & $\begin{array}{l}10,8 \\
27,0\end{array}$ & $\begin{array}{l}6,7 \\
9,1\end{array}$ & $\begin{array}{l}7,1 \\
7,0\end{array}$ & $\begin{array}{r}8,7 \\
35,6\end{array}$ & $\begin{array}{r}7,0 \\
34,6\end{array}$ & $\begin{array}{l}8,9 \\
8,2\end{array}$ \\
\hline & \multicolumn{9}{|c|}{ Experimento 2: $10-20 \mathrm{~cm}$} \\
\hline $\begin{array}{l}\text { Testemunha } \\
\text { Xisto } \\
\text { Escória Mannesman } \\
\text { Escória Dedini } \\
\text { Termofosfato }\end{array}$ & $\begin{array}{l}5,5 \mathrm{~b} \\
5,8 \mathrm{ab} \\
6,1 \mathrm{a} \\
6,0 \mathrm{ab} \\
6,2 \mathrm{a}\end{array}$ & $\begin{array}{l}9 c \\
43 a \\
15 b c \\
24 b \\
13 b c\end{array}$ & $\begin{array}{l}2,5 \\
3,6 \\
2,7 \\
2,5 \\
3,9\end{array}$ & $\begin{array}{l}39 b \\
60 a b \\
60 a b \\
70 a \\
58 a b\end{array}$ & $\begin{array}{l}13 b \\
15 a b \\
20 a b \\
20 a b \\
25 a\end{array}$ & $\begin{array}{l}20 \\
21 \\
17 \\
15 \\
15\end{array}$ & $\begin{array}{l}55 \mathrm{~b} \\
77 \mathrm{ab} \\
82 \mathrm{ab} \\
93 \mathrm{a} \\
87 \mathrm{ab}\end{array}$ & $\begin{array}{r}75 \\
99 \\
99 \\
108 \\
101\end{array}$ & $\begin{array}{l}73 \mathrm{~b} \\
79 \mathrm{ab} \\
83 \mathrm{a} \\
86 \mathrm{a} \\
86 \mathrm{a}\end{array}$ \\
\hline C.V. (\%) & 2,8 & 21,0 & 18,6 & 15,6 & 20,5 & 14,2 & 15,1 & 13,1 & 3,5 \\
\hline $\begin{array}{l}\text { Valor F } \\
\text { D.M.S. a } 5 \%\end{array}$ & $\begin{array}{l}6,0 \\
0,5\end{array}$ & $\begin{array}{l}21,5 \\
13,1\end{array}$ & $\begin{array}{l}3,2 \\
1,7\end{array}$ & $\begin{array}{r}3,6 \\
26,7\end{array}$ & $\begin{array}{r}3,5 \\
11,3\end{array}$ & $\begin{array}{l}2,7 \\
7,4\end{array}$ & $\begin{array}{r}3,4 \\
35,4\end{array}$ & $\begin{array}{r}2,3 \\
37,6\end{array}$ & $\begin{array}{l}7,6 \\
8,3\end{array}$ \\
\hline
\end{tabular}

(1) Médias com letras distintas, na coluna, diferem entre si pelo teste de Tukey a $5 \%$. 
Os efeitos sobre o pH do solo não foram mais significativos em decorrência da elevada saturação por base inicial dos solos. O tratamento com xisto não apresentou efeito sobre o $\mathrm{pH}$, provavelmente por causa da baixa concentração decarbonatos e da baixa reatividade dos silicatos. Por outro lado, o xisto propiciou aumentos significativos no teor de $\mathrm{S}$ do

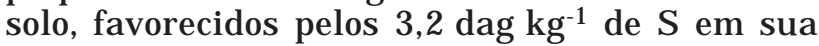
composição.

As fontes utilizadas aumentaram os teores de $\mathrm{Si}$ no solo (Quadro 2). Verificou-se que a escória da Mannesman foi o tratamento que mais liberou Si para o solo, sendo estatisticamente diferente da testemunha na profundidade de $0-10 \mathrm{~cm}$, no experimento 1 , e nas duas profundidades, no experimento 2, seguida do termofosfato que, também, diferiu da testemunha no experimento 2 nas duas profundidades. É preciso lembrar que, no caso do termofosfato, a quantidade aplicada foi inferior à das demais fontes e os teores totais de $\mathrm{Si}$ neste material inferiores aos dos demais.

O xisto é o produto dente os materiais testados que apresenta a maior concentração de Si; no entanto, este Si aparentemente não é solúvel para as plantas porque os teores no solo estão bem próximos aos da testemunha. Esta baixa reatividade do xisto, associado à liberação de $\mathrm{S}$, pode explicar a falta de efeito sobre o $\mathrm{pH}$ do solo. O S do xisto encontra-se principalmente na forma elementar e de sulfeto, no solo estes compostos formam sulfato $\left(\mathrm{SO}_{4}\right)$, podendo baixar o $\mathrm{pH}$, conforme demonstrado por Mello et al. (1989). E mbora não-significativo com relação à testemunha, o tratamento com xisto chegou a apresentar redução do pH no solo.

Verificou-se que o termofosfato foi a fonte mais eficiente na liberação de Si para o solo, pois, na correlação entre o Si aplicado e o teor de Si no solo, observou-se que o xisto liberou 0,58 e 1 \%, a escória da Mannesman 6 e $12 \%$, a escória da Dedini 5 e 4 \% e o termofosfato 8 e $37 \%$ nos experimentos 1 e 2, respectivamente, na camada de $0-10 \mathrm{~cm}$. Na camada de 10-20 cm, observou-se que o xisto liberou 0,2 e $1 \%$, a escória da Mannesman 0,04 e $6 \%$, a escória da Dedini 2 e $2 \%$ e o termofosfato 3 e $18 \%$, nos experimentos 1 e 2 , respectivamente.

\section{Efeito dos tratamentos nas plantas}

Observou-se resposta semelhante com relação ao xisto nas análises do material vegetal, nas quais se percebeu o aumento dos teores deS tanto nas fol has como nos pecíolos (Quadro 3). O termofosfato, ao contrário do xisto, apresentou redução do teor de S na maioria das anál ises do material vegetal. Isto fez com que este tratamento diferissesignificativamente do xisto, com exceção do pecíolo no experimento 1 (Quadro 3). Verificou-se, também, uma redução nos teores de P com a aplicação do termofosfato, sendo esta redução significativa nos pecíolos, quando comparadoà testemunha eao xisto no experimento 1 e, somente ao xisto no experimento 2. I sto se deveà menor solubilidade imediata do termofosfato com relação à fonte de fósforo utilizada nos outros tratamentos (superfosfato triplo). Resultados semelhantes foram obtidos por Pereira (1995) em milho e Prochnow (1996), em que a menor liberação de $\mathrm{P}$ do termofosfato, após sua aplicação, reflete na sua disponi bilidade para as plantas, principal mente quanto se trata de culturas de ciclo curto.

Em relação aos demais elementos, não se verificaram diferenças significativas nos tratamentos, com exceção de alguns elementos em determinadas análises, como o $\mathrm{B}$ na fol ha no experimento 1, o Cu na fol ha no experimento 2 e o $\mathrm{K}$ no pecíolo no experimento 2 , os quais apresentaram diferenças significativas em algum tratamento, sem se repetirem nas demais análises.

\section{Quadro 2. Resultado da análise de $\mathrm{SiO}_{2}$ no solo após a colheita do tomate}

\begin{tabular}{|c|c|c|c|c|}
\hline \multirow{3}{*}{ Tratamento(1) } & \multicolumn{2}{|c|}{ Experimento 1} & \multicolumn{2}{|c|}{ Experimento 2} \\
\hline & \multicolumn{4}{|c|}{ Profundidade $(\mathrm{cm})$} \\
\hline & 0-10 & $10-20$ & 0-10 & $10-20$ \\
\hline & \multicolumn{4}{|c|}{$-\mathrm{SiO}_{2} \mathrm{mg} \mathrm{dm}^{-3}$} \\
\hline $\begin{array}{l}\text { Testemunha } \\
\text { Xisto } \\
\text { Escória Mannesman } \\
\text { Escória Dedini } \\
\text { Termofosfato }\end{array}$ & $\begin{array}{l}53 \mathrm{~b} \\
62 \mathrm{ab} \\
115 \mathrm{a} \\
96 \mathrm{ab} \\
72 \mathrm{ab}\end{array}$ & $\begin{array}{l}36 \\
39 \\
37 \\
57 \\
44\end{array}$ & $\begin{array}{l}84 \mathrm{~b} \\
100 \mathrm{~b} \\
207 \mathrm{a} \\
115 \mathrm{~b} \\
170 \mathrm{a}\end{array}$ & $\begin{array}{l}70 \mathrm{c} \\
90 \mathrm{bc} \\
134 \mathrm{a} \\
90 \mathrm{bc} \\
113 \mathrm{ab}\end{array}$ \\
\hline C.V. (\%) & 32,5 & 21,4 & 13,2 & 15,9 \\
\hline $\begin{array}{l}\text { Valor F } \\
\text { D.M.S. a } 5 \%\end{array}$ & $\begin{array}{r}3,8 \\
58,5\end{array}$ & $\begin{array}{r}3,5 \\
20,5\end{array}$ & $\begin{array}{l}33,4 \\
40,4\end{array}$ & $\begin{array}{r}9,6 \\
35,7\end{array}$ \\
\hline
\end{tabular}

(1) Médias com letras distintas, na coluna, diferem entre si pelo teste de Tukey a $5 \%$. 
Quadro 3. Resultados das análises de macro e micronutrientes de folhas e pecíolos do tomateiro coletadas na época do primeiro fruto maduro (cerca de 75 dias após o transplante)

\begin{tabular}{|c|c|c|c|c|c|c|c|c|c|c|c|}
\hline \multirow[t]{3}{*}{ Tratamento(1) } & $\mathbf{N}$ & $\mathbf{P}$ & $\mathbf{K}$ & $\mathrm{Ca}$ & Mg & $\mathbf{S}$ & B & $\mathbf{C u}$ & $\mathbf{F e}$ & Mn & $Z \mathbf{n}$ \\
\hline & & & $\mathrm{g} \mathrm{ko}$ & $g^{-1}-$ & & - & \multicolumn{5}{|c|}{$\mathrm{mg} \mathrm{kg}^{-1}$} \\
\hline & \multicolumn{11}{|c|}{ Experimento 1: folha } \\
\hline $\begin{array}{l}\text { Testemunha } \\
\text { Xisto } \\
\text { Escória Mannesman } \\
\text { Escória Dedini } \\
\text { Termofosfato }\end{array}$ & $\begin{array}{l}34,6 \\
32,0 \\
31,5 \\
33,7 \\
32,4\end{array}$ & $\begin{array}{l}6,5 \\
5,0 \\
4,8 \\
5,2 \\
4,3\end{array}$ & $\begin{array}{l}47,9 \\
40,0 \\
43,7 \\
44,7 \\
43,9\end{array}$ & $\begin{array}{l}41,5 \\
38,5 \\
37,2 \\
40,6 \\
38,8\end{array}$ & $\begin{array}{l}7,8 \\
7,4 \\
8,1 \\
8,1 \\
7,8\end{array}$ & $\begin{array}{l}6,8 \mathrm{ab} \\
7,8 \mathrm{a} \\
6,5 \mathrm{ab} \\
7,0 \mathrm{ab} \\
6,3 \mathrm{~b}\end{array}$ & $\begin{array}{l}91 \mathrm{a} \\
81 \mathrm{ab} \\
70 \mathrm{~b} \\
79 \mathrm{ab} \\
90 \mathrm{a}\end{array}$ & $\begin{array}{l}541 \\
600 \\
563 \\
553 \\
487\end{array}$ & $\begin{array}{l}161 \\
159 \\
202 \\
187 \\
190\end{array}$ & $\begin{array}{r}105 \\
103 \\
90 \\
74 \\
95\end{array}$ & $\begin{array}{l}16 \\
16 \\
15 \\
15 \\
17\end{array}$ \\
\hline C.V. (\%) & 3,3 & 17,7 & 10,8 & 7,9 & 6,2 & 6,7 & 8,1 & 17,2 & 22,8 & 17,4 & 12,4 \\
\hline \multirow[t]{2}{*}{$\begin{array}{l}\text { Valor F } \\
\text { D.M.S. a } 5 \%\end{array}$} & $\begin{array}{l}3,1 \\
3,3\end{array}$ & $\begin{array}{l}1,8 \\
2,7\end{array}$ & $\begin{array}{r}0,8 \\
14,2\end{array}$ & $\begin{array}{l}0,7 \\
9,2\end{array}$ & $\begin{array}{l}0,8 \\
1,4\end{array}$ & $\begin{array}{l}3,6 \\
1,3\end{array}$ & $\begin{array}{r}3,9 \\
19,7\end{array}$ & $\begin{array}{r}0,4 \\
281,3\end{array}$ & $\begin{array}{r}0,5 \\
122,5\end{array}$ & $\begin{array}{r}1,3 \\
48,7\end{array}$ & $\begin{array}{l}0,3 \\
5,9\end{array}$ \\
\hline & \multicolumn{11}{|c|}{ Experimento 1: peciolo } \\
\hline $\begin{array}{l}\text { Testemunha } \\
\text { Xisto } \\
\text { Escória Mannesman } \\
\text { Escória Dedini } \\
\text { Termofosfato }\end{array}$ & $\begin{array}{l}13,5 \\
13,9 \\
13,7 \\
14,6 \\
14,1\end{array}$ & $\begin{array}{l}3,8 \mathrm{a} \\
3,2 \mathrm{ab} \\
2,2 \mathrm{c} \\
2,8 \mathrm{bc} \\
2,3 \mathrm{c}\end{array}$ & $\begin{array}{l}35,1 \\
22,5 \\
23,3 \\
32,0 \\
32,6\end{array}$ & $\begin{array}{l}27,0 \\
25,3 \\
23,9 \\
26,9 \\
25,1\end{array}$ & $\begin{array}{l}6,2 \\
5,2 \\
5,2 \\
6,7 \\
6,3\end{array}$ & $\begin{array}{l}2,8 \\
3,5 \\
2,3 \\
3,5 \\
2,8\end{array}$ & $\begin{array}{l}49 \\
49 \\
44 \\
50 \\
48\end{array}$ & $\begin{array}{r}111 \\
109 \\
91 \\
115 \\
87\end{array}$ & $\begin{array}{l}59 \\
58 \\
59 \\
61 \\
54\end{array}$ & $\begin{array}{l}68 \\
55 \\
47 \\
60 \\
57\end{array}$ & $\begin{array}{l}40 \\
30 \\
28 \\
30 \\
34\end{array}$ \\
\hline C.V. (\%) & 6,1 & 7,4 & 23,3 & 6,6 & 12,5 & 15,4 & 8,5 & 17,7 & 16,5 & 19,0 & 18,6 \\
\hline \multirow[t]{2}{*}{$\begin{array}{l}\text { Valor F } \\
\text { D.M.S. a } 5 \%\end{array}$} & $\begin{array}{l}0,5 \\
2,6\end{array}$ & $\begin{array}{r}20,9 \\
0,6\end{array}$ & $\begin{array}{r}1,7 \\
20,2\end{array}$ & $\begin{array}{l}1,3 \\
5,1\end{array}$ & $\begin{array}{l}2,0 \\
2,2\end{array}$ & $\begin{array}{l}2,8 \\
1,4\end{array}$ & $\begin{array}{r}0,9 \\
12,1\end{array}$ & $\begin{array}{r}1,1 \\
54,2\end{array}$ & $\begin{array}{r}0,2 \\
28,5\end{array}$ & $\begin{array}{r}1,1 \\
32,5\end{array}$ & $\begin{array}{r}1,5 \\
18,2\end{array}$ \\
\hline & \multicolumn{11}{|c|}{ Experimento 2: fol ha } \\
\hline $\begin{array}{l}\text { Testemunha } \\
\text { Xisto } \\
\text { Escória Mannesman } \\
\text { Escória Dedini } \\
\text { Termofosfato }\end{array}$ & $\begin{array}{l}40,8 \\
38,3 \\
37,2 \\
39,3 \\
37,7\end{array}$ & $\begin{array}{l}4,3 \\
4,7 \\
4,4 \\
4,2 \\
4,1\end{array}$ & $\begin{array}{l}29,0 \\
31,5 \\
28,7 \\
27,4 \\
30,4\end{array}$ & $\begin{array}{l}36,1 \\
42,6 \\
40,7 \\
38,8 \\
39,3\end{array}$ & $\begin{array}{l}4,4 \\
4,6 \\
4,5 \\
4,6 \\
4,5\end{array}$ & $\begin{array}{l}6,1 \mathrm{ab} \\
7,6 \mathrm{a} \\
6,9 \mathrm{ab} \\
6,3 \mathrm{ab} \\
5,5 \mathrm{~b}\end{array}$ & $\begin{array}{l}429 \\
488 \\
453 \\
358 \\
412\end{array}$ & $\begin{array}{l}1.015 \mathrm{ab} \\
1.106 \mathrm{a} \\
1.007 \mathrm{ab} \\
904 \mathrm{~b} \\
1.121 \mathrm{a}\end{array}$ & $\begin{array}{l}406 \\
419 \\
350 \\
351 \\
367\end{array}$ & $\begin{array}{l}802 \\
930 \\
854 \\
832 \\
851\end{array}$ & $\begin{array}{l}758 \\
903 \\
770 \\
723 \\
823\end{array}$ \\
\hline C.V. (\%) & 4,9 & 5,9 & 10,1 & 6,3 & 4,4 & 9,2 & 11,3 & 6,5 & 18,5 & 7,8 & 13,1 \\
\hline \multirow[t]{2}{*}{$\begin{array}{l}\text { Valor F } \\
\text { D.M.S. a } 5 \%\end{array}$} & $\begin{array}{l}1,3 \\
5,6\end{array}$ & $\begin{array}{l}1,6 \\
0,8\end{array}$ & $\begin{array}{l}0,6 \\
8,9\end{array}$ & $\begin{array}{l}2,1 \\
7,5\end{array}$ & $\begin{array}{l}0,5 \\
0,6\end{array}$ & $\begin{array}{l}4,1 \\
1,7\end{array}$ & $\begin{array}{r}2,3 \\
145,0\end{array}$ & $\begin{array}{r}3,9 \\
200,9\end{array}$ & $\begin{array}{r}0,5 \\
208,6\end{array}$ & $\begin{array}{r}1,1 \\
199,8\end{array}$ & $\begin{array}{r}1,0 \\
309,7\end{array}$ \\
\hline & \multicolumn{11}{|c|}{ Experimento 2: pecíolo } \\
\hline $\begin{array}{l}\text { Testemunha } \\
\text { Xisto } \\
\text { Escória Mannesman } \\
\text { Escória Dedini } \\
\text { Termofosfato }\end{array}$ & $\begin{array}{l}14,0 \\
14,2 \\
13,7 \\
13,6 \\
13,8\end{array}$ & $\begin{array}{l}4,3 a b \\
5,4 a \\
4,4 a b \\
4,5 a b \\
3,7 b\end{array}$ & $\begin{array}{l}57,2 \mathrm{ab} \\
59,6 \mathrm{a} \\
48,0 \mathrm{~b} \\
55,8 \mathrm{ab} \\
58,8 \mathrm{ab}\end{array}$ & $\begin{array}{l}32,4 \\
33,0 \\
31,8 \\
31,8 \\
33,6\end{array}$ & $\begin{array}{l}5,6 \\
5,2 \\
5,1 \\
5,4 \\
5,8\end{array}$ & $\begin{array}{l}2,3 \mathrm{ab} \\
2,6 \mathrm{a} \\
2,2 \mathrm{ab} \\
2,2 \mathrm{ab} \\
1,8 \mathrm{~b}\end{array}$ & $\begin{array}{l}59 \\
57 \\
58 \\
66 \\
63\end{array}$ & $\begin{array}{l}139 \\
133 \\
113 \\
117 \\
148\end{array}$ & $\begin{array}{l}79 \\
71 \\
74 \\
74 \\
89\end{array}$ & $\begin{array}{l}131 \\
116 \\
111 \\
116 \\
121\end{array}$ & $\begin{array}{l}187 \\
181 \\
151 \\
162 \\
180\end{array}$ \\
\hline C.V. (\%) & 3,8 & 9,2 & 6,5 & 6,0 & 8,9 & 8,7 & 11,2 & 16,6 & 10,4 & 9,5 & 14,6 \\
\hline $\begin{array}{l}\text { Valor F } \\
\text { D.M.S. a } 5 \%\end{array}$ & $\begin{array}{l}0,5 \\
1,6\end{array}$ & $\begin{array}{l}5,2 \\
1,2\end{array}$ & $\begin{array}{r}3,7 \\
10,8\end{array}$ & $\begin{array}{l}0,3 \\
5,8\end{array}$ & $\begin{array}{l}0,9 \\
1,4\end{array}$ & $\begin{array}{l}5,5 \\
0,6\end{array}$ & $\begin{array}{r}0,7 \\
20,2\end{array}$ & $\begin{array}{r}1,1 \\
64,6\end{array}$ & $\begin{array}{r}1,8 \\
24,0\end{array}$ & $\begin{array}{r}1,1 \\
33,7\end{array}$ & $\begin{array}{r}0,8 \\
75,1\end{array}$ \\
\hline
\end{tabular}

(1) Médias com letras distintas, na coluna, diferem entre si pelo teste de Tukey a $5 \%$.

Assim como no solo, o tratamento com a escória da Mannesman foi o que apresentou maiores teores de Si nas folhas do tomateiro, seguido pelo tratamento da escória Dedini (Quadro 4). O termofosfato também apresentou resultados próximos aos das escórias, demonstrando a grande li iberação deSi por este produto, já que apresentava a menor concentração de Si em sua composição e a dose aplicada também foi menor.

O xisto também aumentou oteor deSi nas fol has das plantas, diferindo da testemunha. O aumento de Si nas plantas foi mais expressivo que no solo, o que fez com que houvesse maior dispersão dos pontos na correlação entre solo e planta. Mesmo assim, observa-se, nas figuras 1 e 2, que houve razoável correlação entre oSi liberado ao sol o e oSi absorvido pelas plantas.

No caso dos tratamentos com escórias, o extrator, além de extrair o Si "disponível" do solo, também podeextrair oSi das escórias queainda não reagiram no solo e, portanto, superestimar a eficiência agronômica destes. Korndörfer et al. (1999) demonstraram a importância de se escolher um extrator adequado para a análise deSi no solo, neste 
Quadro 4. Resultado da análise de Si nas plantas do tomateiro coletadas na época do primeiro fruto maduro (cerca de 75 dias após o transplante)

\begin{tabular}{|c|c|c|c|c|}
\hline \multirow{2}{*}{ Tratamento(1) } & \multicolumn{2}{|c|}{ Experimento 1} & \multicolumn{2}{|c|}{ Experimento 2} \\
\hline & Folha & Pecíolo & Folha & Pecíolo \\
\hline & & 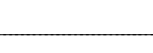 & 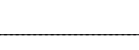 & 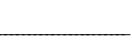 \\
\hline Testemunha & $0,18 \mathrm{~b}$ & $0,16 \mathrm{bc}$ & $2,27 \mathrm{c}$ & $0,42 b$ \\
\hline Xisto & $1,04 \mathrm{a}$ & $0,28 \mathrm{bc}$ & $2,97 \mathrm{~b}$ & $0,69 a b$ \\
\hline Esc. Mannesman & $1,51 \mathrm{a}$ & $0,39 \mathrm{ab}$ & $3,72 \mathrm{a}$ & $1,06 \mathrm{a}$ \\
\hline Esc. Dedini & $1,16 \mathrm{a}$ & $0,53 a$ & $3,21 a b$ & 0,91 a \\
\hline Termofosfato & $1,08 \mathrm{a}$ & $0,11 \mathrm{c}$ & $3,05 \mathrm{~b}$ & $0,82 a$ \\
\hline C.V. (\%) & 28,3 & 35,7 & 16,8 & 21,4 \\
\hline Valor F & 12,1 & 10,76 & 2,38 & 8,51 \\
\hline D.M.S. a $5 \%$ & 0,64 & 0,24 & 0,65 & 0,38 \\
\hline
\end{tabular}

(1) Médias com letras distintas, na coluna, diferem entre si ao teste de Tukey a $5 \%$.

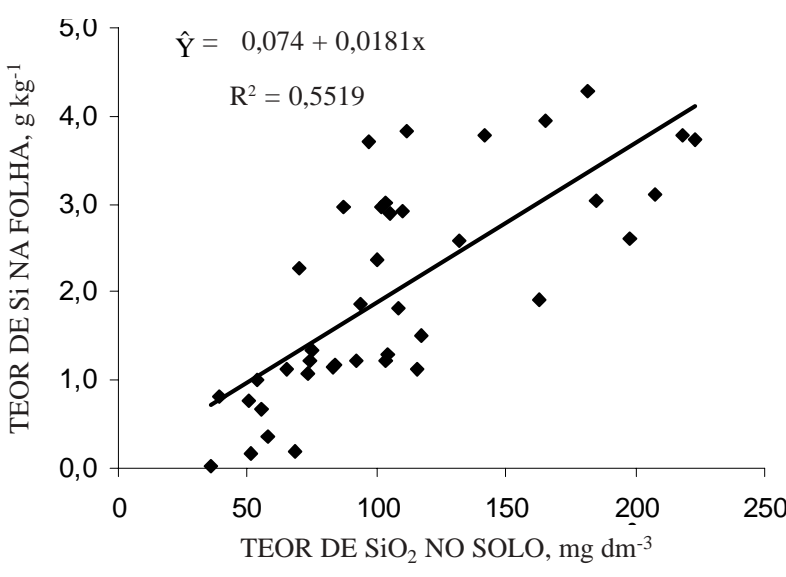

Figura 1. Correlação entre silício "disponível" no solo e teor de silício das folhas do tomateiro.

caso, o ácido acético 0,5 mol L-1 apresentou boa correlação entreoSi liberado ao sol o eo Si absorvido pelas plantas. Em outro trabalho, Korndörfer \& Gascho (1999), usando diferentes escórias e Wollastonita (silicato de cálcio), também obtiveram boa correlação entre Si absorvido e Si liberado no solo extraído pelo ácido acético 0,5 mol L-1; observaram, porém que as escórias apresentaram maiores teores de Si no solo proporcionalmente ao absorvido, enquanto a Wollastonita apresentou maiores teores de Si absorvido pelas plantas em relação ao extraído do solo.

\section{Efeito das fontes de silício na produção de tomate}

Apesar das elevadas produtividades, não foi possível observar diferenças significativas na produção de tomate (Quadro 5). Notou-se, no entanto, ligeira superioridade dos tratamentos nos experimentos, em comparação à testemunha. E stes resultados contrariam outros em que são

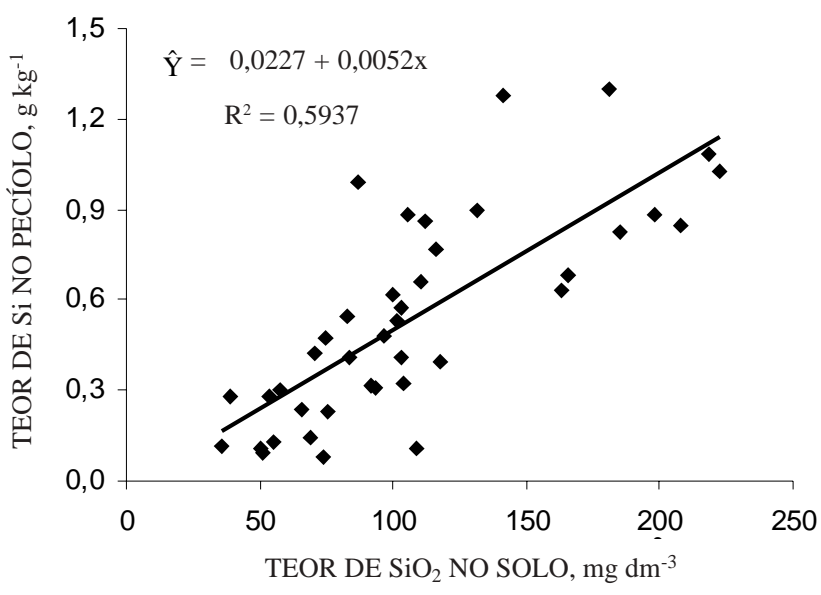

Figura 2. Correlação entre silício "disponível" no solo e teor de silício dos pecíolos do tomateiro.

demonstrados os efeitos das escórias sobre a produção agrícola (Anderson et al., 1987; Rodriguez et al., 1994; Prado \& Fernandes, 2000). A ausência

\section{Quadro 5. Resultado da produção de tomate}

\begin{tabular}{lcc}
\hline \multicolumn{1}{c}{ Tratamento(1) } & Experimento 1 Experimento 2 \\
\cline { 2 - 2 } & \multicolumn{2}{c}{ t ha-1 $^{-1}$} \\
Testemunha & 72,2 & 107,3 \\
Xisto & 92,8 & 106,3 \\
Escória Mannesman & 76,6 & 116,1 \\
Escória Dedini & 83,2 & 121,5 \\
Termofosfato & 84,1 & 121,8 \\
C.V. (\%) & 10,8 & 8,9 \\
Valor F & 3,1 & 2,2 \\
D.M.S. a 5 \% & 21,1 & 22,9
\end{tabular}

(1) Médias com letras distintas, na coluna, diferem entre si ao teste de Tukey a $5 \%$. 
de pragas e doenças durante a fase experimental e os altos teores iniciais de Si no solo podem ter contribuído para minimizar os efeitos do Si sobre a produção. O arroz éa única cultura que apresentou níveis críticos para o Si, segundo Korndörfer et al. (2001), estimados em torno de $20 \mathrm{mg} \mathrm{kg}^{-1}$ de solo.

\section{CONCLUSÕES}

1. As escórias, o xisto e o termofosfato foram capazes de liberar Si para o solo e aumentar a absorção de Si pelas plantas do tomateiro; no entanto, esta maior absorção foi insuficiente para influir na produtividade.

2. O xisto, apesar do alto teor de $\mathrm{SiO}_{2}$ na sua composi ção não foi capaz de corrigir a acidez do solo, tal como aconteceu com o termofosfato eas escórias.

\section{LITE RATURA CITADA}

ALCARDE, J .C. Corretivos da acidez dos solos: características e interpretações técnicas. São Paulo, Associação Nacional para Difusão de Adubos, 1992. (Boletim Técnico, 6)

ANDERSON, D.L.; J ONES, D.B. \& SNYDER, G.H. Response of a rice sugarcane rotation to calcium silicate slag on Everglades Histosols. Agron. J ., 79:531-535, 1987.

BERGER, K.C. \& TRUOG, E. Boron determination in soils and plants using the quinazizarin reaction. Ind. Eng. Chem., 11:540-545, 1939.

BIGARELLA, J J. Geologia da formação Iratí. In: SI MPÓSIO SOBRE CIÊNCIA E TECNOLOGIA DO XISTO, Rio de J aneiro, 1975. Anais. Rio de J aneiro, Academia Brasileira de Ciência, 1975. p.1-79.

COELHO, P.E. Da escória ao vidro. R. Limpeza Públ., 49:36-45, 1998.

EPSTEIN, E. The anomaly of silicon in plant biology. Proc. Nat. Ac. Sci., 91:11-17, 1994.

FREIRE, F.M.; NOVAIS, R.F.; SOARES, P.C.; COSTA, L.M. \& FARIA, E.A. Calagem, adubação orgânica e manejo da água no controle da toxicidade de ferro em arroz irrigado. Ceres, 32:162-169, 1985.

FOX, R.L. \& SILVA, J .A. Symptoms of plant malnutrition silicon an ergonomically essential nutrient for sugarcane. Hawaii, University of Hawaii, 1978. p.85. (Série, 8)

GRATT, L.B. Risk analysis of hazardous materials in oil shale. J . Hazard. Mat., 10:317-334, 1985.

KILMER, V.J . Silicon. In: BLACK, C.A., ed. Methods of soil analysis. Part 1. Madison, Americam Society of Agronomy, 1965. p.959-962. (Agronomy, 9)

KORNDÖRFER, G.H. \& GASCHO, G.J . Avaliação de fontes de silício para o arroz. In: CONGRESSO BRASILEIRO DE ARROZ IRRIGADO, 1., Pelotas, 1999. Anais. Pelotas, Empresa Brasileira de Pesquisa Agropecuária, 1999. p.313316.
KORNDÖRFER, G.H.; COELHO, N.M.; SNYDER, G.H. \& MIZUTANI, C.T. Avaliação de métodos de extração de silício para solos cultivados com arroz de sequeiro. R. Bras. Ci. Solo, 23:101-106, 1999.

KORNDÖRFER, G.H.; SNYDER, G.H.; ULLOA, M; POWEL, G. $\&$ DATNOFF, L.E. Calibration of soil and plant silicon analysis for rice production. J. Plant Nut., 24:1071-1084, 2001.

LINDSAY, W.L. \& MORVELL, W.A. Development of a DTPA soil test for zinc, iron, manganese and copper. Soil Sci. Soc. Am. J ., 42:421-428, 1978.

MALAVOLTA, E.; VITTI, G.C. \& OLIVEIRA, S.A. Avaliação do estado nutricional das plantas: princípios e aplicações. Piracicaba, POTAFOS, 1997. 201p.

MELLO, F.A.F.; BRASIL SOBRINO, M.O.C.; ARZOLLA, S.; SILVEIRA, R.I.; COBRA NETO, A. \& KIEHL, J.C. Fertilidade do solo. 3 ed. São Paulo, Nobel, 1989. 400p.

PEREI RA, H.S. Efeitos de fontes de fósforo, associadas à calagem e micronutriente nos atributos quími cos de sol o e na cultura do milho. Piracicaba, Escola Superior de Agricultura "Luiz de Queiroz", 1995. 83p. (Tese de Mestrado)

PRADO, R.M. \& FERNANDES, F.M. Resposta da cana-de-açúcar à aplicação da escória de siderurgia como corretivo de acidez do solo. R. Bras. de Ci. Solo, 25:199-207, 2000.

PRIEN, C. Current developments in world oil shale technology. In: SIMPÓSIO SOBRE CIÊNCIA E TECNOLOGIA DO XISTO, Rio de J aneiro, 1975, Anais. Rio de J aneiro, Academia Brasileira de Ciência, 1975. p.1-41.

PROCHNOW, L.I. Disponibilidade do fósforo da fração solúvel em citrato neutro de amônio einsolúvel em água de fosfatos acidulados. Piracicaba, Escola Superior deAgricultura “Luiz de Queiroz", 1996. 157p. (Tese de Doutorado)

RAIJ , B. van \& QUAGGIO, J.A. Métodos de análise de solo para fins de fertilidade. Campinas, Instituto Agronômico de Campinas, 1983. 31p. (IAC - Boletim Técnico, 81)

REDDY, K.J . \& LINDSAY, W.L. The solubility relationships of calcium and magnesium minerals in processed oil shells. J . Environ. Qual., 15:1-4, 1986.

RODRIGUEZ, M.; LOPEZ, F.A.; PINTO, M.; BALCÁZAR, N. \& BESGA, G. Basic Linz-Donawtz slag as liming agent for pastureland. Agron. J ., 86:904-909, 1994.

SMITH, B.F.L. The determination of silicon in ammonium oxalate extracts of soils. Comm. Soil Sci. Plat. Anal., 15:199-204, 1984.

STARK, J.M. \& REDENTE, E.F. Trace element and salt movement in retorted oil shale disposal sites. J. Environ. Qual., 15:282-288, 1986.

TRANI, P.E. \& RAIJ, B. van. Hortaliças. In: RAIJ, B. van; R.; CANTARELLA; QUAGGIO, J.A. \& FURLANI, A.M.C. Recomendação de adubação e calagem para o Estado de São Paulo. Campinas, Instituto Agronômico de Campinas, 1996. p.155-186 . (IAC. Boletim Técnico, 100)

VITTI, G.C. Avaliação e interpretação do enxofre no solo e na planta. J aboticabal, FUNEP, 1989. 37p. 